\title{
Bus Crashes in Iran
}

\section{Mohammad Parvaresh-Masoud, MScN, BScN, $\mathrm{PhD}$ (student); ${ }^{1}$ Hamid Asayesh, $\mathrm{MScN}, \mathrm{BScN}^{2}$}

\author{
1. Tehran University of Medical Sciences, \\ School of Nursing \& Midwifery, Tehran, Iran \\ 2. Faculty of Paramedical Sciences, Qom \\ University of Medical Sciences, Qom, Iran \\ Correspondence: \\ Hamid Asayesh, MScN, BScN \\ Faculty of Paramedical Sciences \\ Qom University of Medical Sciences \\ Qom, Iran \\ E-mail: hasayesh@gmail.com \\ Conflicts of interest: none
}

Received: July 9, 2017

Revised: September 23, 2017

Accepted: October 21, 2017

Online publication: February 27, 2018

doi:10.1017/S1049023X1800016X
Parvaresh-Masoud M, Asayesh H. Bus crashes in Iran. Prehosp Disaster Med. 2018; 33(2):227.

Dear Editor,

We wish to share our experiences (2006-2014) with bus crashes in the prehospital setting. We had observed a number of these types of accidents over many years in the Qom Province of Iran.

Also, we had been responsible for evaluating several bus accidents scenes. It was found that:

1. Many of the accidents took place on main roads and were usually at top speed. There was evidence for significant mechanism of injury.

2. The scenes were busy and far from the safe points. Confirmation of the exact numbers of casualties and their condition was difficult. Fire and Rescue Service teams and police were present. In these situations, early triage is essential; triage of the victims was difficult, unfortunately, because of crowding. Also, some of the victims were trapped inside the buses.

3. Many of the victims suffered from multiple traumas, including head injury. Many of them didn't fasten their seatbelts. It is necessary to consider measures to minimize injuries and other damages in the case of an accident. Passengers should also be encouraged to fasten their seat belts when buses are in motion.

4. In most night accidents, drowsiness was the main cause. The driver was seriously injured or killed in those accidents. So, it is necessary to pay attention to rules and avoid prolonged driving without rest or an auxiliary driver.

5. In most accidents, there were no other vehicles other than the bus. There were many reasons such as speed, losing control of the bus and veering left or right, drowsiness, and other factors that were the cause of these accidents. It should be noted that the role of established road safety law is very important. With the measures which have been taken by the Iranian police, many punishments are considered for drivers who are in violation of the law, including being banned from driving.

6. In almost all of the bus accidents evaluated, a specific type of bus was involved. This, of course, has led to a conflict between the company, the traffic police, and the Iranian standards organization.

Sincerely,

Mohammad Parvaresh-Masoud, $\mathrm{MScN}, \mathrm{BScN}, \mathrm{PhD}$ (student)

Hamid Asayesh, MScN, BScN 